\title{
3D FE ANALYSIS OF THE BEHAVIOR OF ELLIPTICAL CRACKS ON ORTHOPEDIC CEMENT OF THE TOTAL HIP PROSTHESIS
}

\author{
Ali Benouis \\ LMPM, Department of Mechanics, Faculty of Engineering, University of Sidi-Bel-Abbes, Algeria and \\ University of Saida, Saïda, Algeria; e-mail: aly_ouis@hotmail.fr \\ Mohammed El Sallah Zagane \\ LMPM, Department of Mechanics, Faculty of Engineering, University of Sidi-Bel-Abbes, Algeria \\ AbDelkader Boulenouar \\ Djillali Liabes University of Sidi Bel-Abbes, Mechanical Engineering Department, LMRS, Algeria \\ Boualem Serier, Mohamed Elnedhir Belgherras \\ LMPM, Department of Mechanics, Faculty of Engineering, University of Sidi-Bel-Abbes, Algeria
}

\begin{abstract}
An explicit analysis conducted on the crack behavior in chirurgical cement (Polymethylmethacrylate - PMMA) used for Total Hip Prosthesis (THP) is of great importance in collecting information about the nature of the phenomenon of loosening of the cement application. The rupture of the orthopedic cement is practically the main cause of this loosening. Understanding different rupture mechanisms give a great value in advancing the durability of the cemented total prosthesis. The purpose of this study is to analyse cracks behavior, initiated in the cement that links the femoral-stem with the bone, using the Finite Element Analysis Method (FEM). The present study brings into focus the variation of the stress intensity factor in modes I, II and III. This rupture criterion is used according to the nature of crack, its orientation and its location in the orthopedic cement. At first, the level and distribution of the equivalent von Mises stress is analysed, which is induced in the medial, proximal and distal parts of the bone cement. Then, the behavior of different geometric forms of an elliptical crack is evaluated which are located and initiated within the body of these three parts.
\end{abstract}

Keywords: cement, implant, crack size, stress intensity factors (SIFs), X-FEM

\section{Introduction}

The bone cement does not act as a glue, but rather as a filling material. Currently, the most common bone cement material is polymethylmethacrylate (PMMA), which is a self-curing polymer compound. In the assembly method, the bone cement is used to connect the hip prosthesis with the femur. The cemented type of Total Hip Replacement (THR) offers a better stress distribution in femur compared to a cementless type. In addition, the hip prosthesis with a shorter stem distributes stresses evenly in the femur. Also, different cancellous density does not significantly affect the stresses. Fatigue failure of the cement mantle have been identified as a possible loosening mechanism for the prosthesis, which can lead to revision surgery. In vivo, surface morphology fracture of the bone cement, related to PMMA fracture micromechanics, despite the higher cement stresses with deboned stems, polished prostheses do not provoke the damage accumulation failure scenario, according to studies which used the extrapolation method to predict the creep behavior of the PMMA bone cement (Topoleski et al., 1990; Lennon et al., 2004; Morgan et al., 2003). Benouis et al. (2016) used 2D-FEM to analyse the behavior of cracks interaction with the orthopedic cement by computing SIFs. Benbarek et al. (2013) 
used numerical analysis to examine the orthopedic cement on the acetabular part. Specifically, the behavior of a crack was examined, emanating from a cavity that was found in several locations in the cement, in order to examine the variation of the SIF, loading, and orientation, and finally to predict the angle and optimum loading for crack propagation, using X-FEM (The Extended Finite Element Method). Abdel-Wahab and Silberschmidt (2011) experimentally and numerically studied the dynamic behavior of a fracture impact in the cortical bone tissue, using X-FEM. Another study by Bouziane et al. (2013) showed that the stress intensity factor of a crack, emanating from a cavity, was higher than the one emanating from an inclusion. Ramos et al. (2013) experimentally observed that the position of an implant in the femur and assemblage with the femoral canal were two important issues of the formation mechanism of cracks between the two surfaces (os-cement, cement-implant). Griza et al. (2013) analysed with FEM the stress distribution of the acetabular part in the PTH using screw fixation. The analysis showed that it took a large amount of computational force to predict screw fracture in the case of the unbounded metal-backed and bone interface. Taylor et al. (2003) used analytical and numerical methods to predict damage of the bone. Najafi et al. (2011) simulated the presence of micro-cracks in the cortical bone. It was proved that the propagation of those cracks was strongly influenced by the bone density, thus, suggesting that the fracture toughness of the bone should be provided, at least in part, in order that bone density could be quantified. Benouis et al. (2015) presented a numerical model of the crack propagation trajectory in the cement of the acetabular part. The crack direction is evaluated as a function of displacement extrapolation and the strain energy density criterion. The low-modulus bone cement of the total hip prosthesis, combined with its mechanical behavior, determines, inter alia, the lifetime of these prostheses. Several experimental procedures have been conducted on the cement, showing the existence of cracks emanating from cavities within the body (McCormack and Prendergast, 1999). These cracks are mainly responsible for the loosening of the total hip prostheses.

This study aims to analyse the behavior of different geometrical forms of elliptical cracks in the orthopedic cement of the femur THP, and to compute the evolution of SIFs at the cracks tip using X-FEM. The effects of the location and orientation of these cracks are highlighted.

\section{Methods}

\subsection{Geometry}

There is currently a variety of product types in the global market of total hip replacement, which are: CMK, BM, FRAM A, etc. For the experimental part of this study, CMK3 has been used (third generation of Charnley KERBOULL prosthesis) due to its availability in the local market. In this study, three-dimensional (3D) Finite Element Method (FEM) has been used in order to examine the behavior of cracks initiated in the bone cement with femoral implant Charnley (Fig. 1).

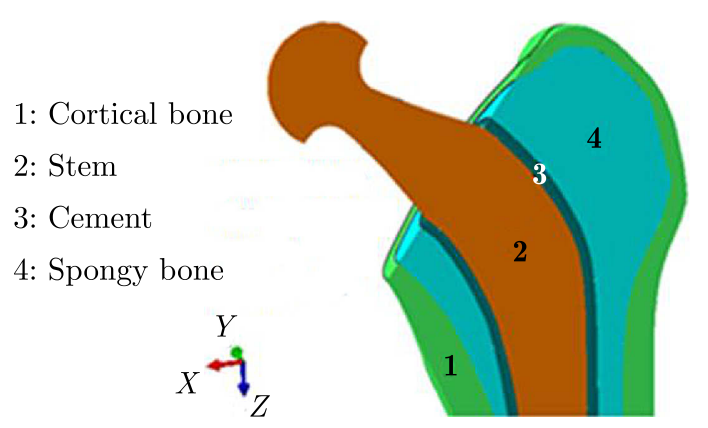

Fig. 1. Three-dimensional femur stems for Charnley 


\subsection{Finite element model}

Three-dimensional (3D) finite element models have been produced for femur, bone cement, implant, and meshed using C3D4 (a 4 node linear tetrahedron). The whole model (stem, bone cement, and femur) has been discredited in 1173459 elements as shown in Fig. 2. To assure reliability of the results, an extremely fine mesh has been imposed around the region of cement cracks.
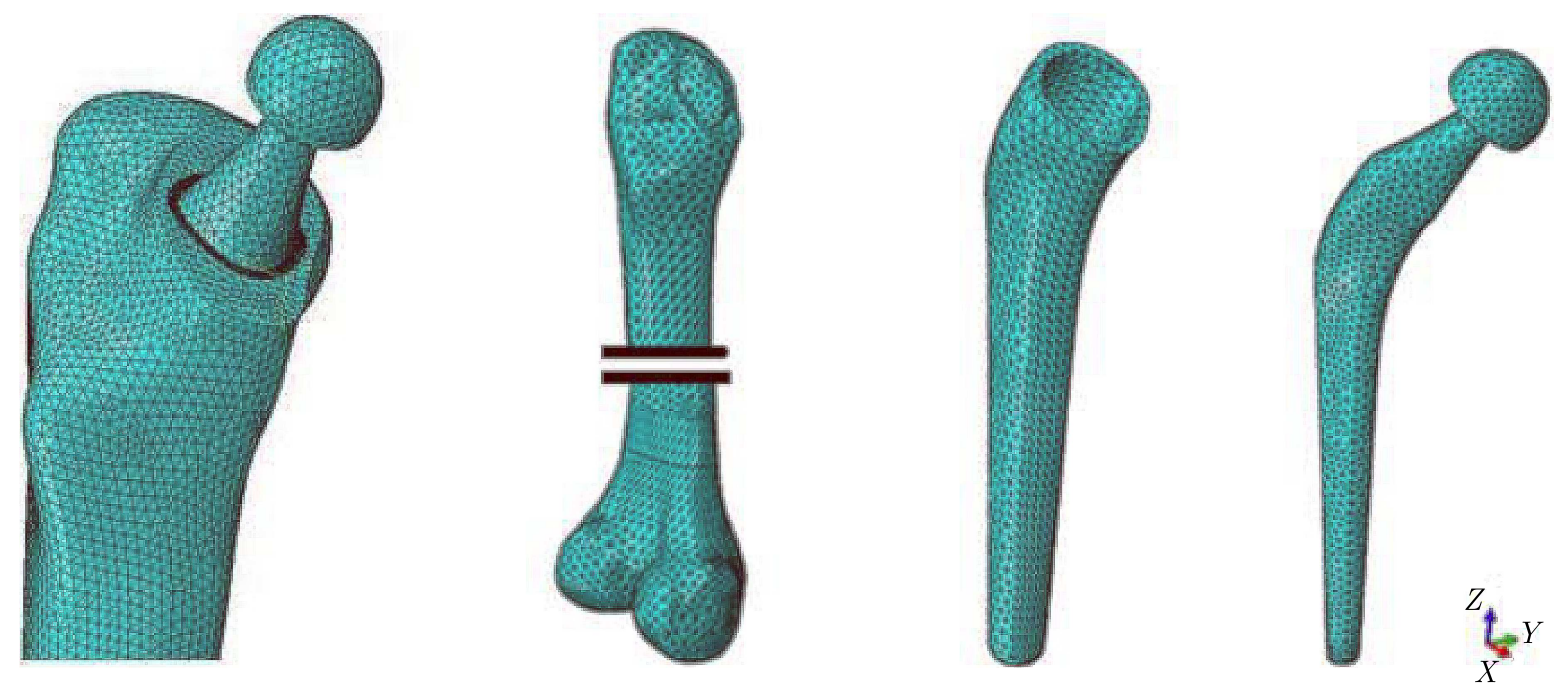

Fig. 2. Boundary conditions and muscle-forces applied in the THP

\subsection{Material model}

Mechanical properties of the materials are presented in Table 1 . The cortical bone is considered as a transversely isotropic elastic material, whereas the spongy bone, cement and Charnley stem, are considered as linear isotropic elastic materials. To assign the material properties to the cortical bone, elastic properties are inserted into ABAQUS. Cement properties are: tensile strength $25 \mathrm{MPa}$, compressive strength $80 \mathrm{MPa}$ (Rodriquez et al., 2014), shear strength $40 \mathrm{MPa}$ (Merckx, 1993) and fatigue (108 cycles) 14 MPa (Pilliar et al., 1982; Soltész, 1994). Ries et al. (2006) found that the critical stress intensity factors $K_{I C}$ are between $0.96 \mathrm{MPa} \sqrt{\mathrm{m}}$ to $1.76 \mathrm{MPa} \sqrt{\mathrm{m}}$.

Table 1. Material, properties of THP (Waanders et al., 2012)

\begin{tabular}{|l|c|c|c|}
\hline $\begin{array}{c}\text { Part of } \\
\text { model }\end{array}$ & $\begin{array}{c}\text { Elastic modulus } \\
{[\mathrm{GPa}]}\end{array}$ & $\begin{array}{c}\text { Poisson's ratio } \\
{[-]}\end{array}$ & $\begin{array}{c}\text { Density } \\
{\left[\mathrm{kg} / \mathrm{m}^{3}\right]}\end{array}$ \\
\hline \hline Stem & 210 & 0.3 & 7900 \\
\hline Cement & 2.4 & 0.3 & 1200 \\
\hline Cancellous bone & 0.4 & 0.3 & 1990 \\
\hline Cortical bone & $\begin{array}{c}E_{x}, E_{y}=7.0, E_{z}=11.5 \\
G_{x y}=2.6, G_{y z}, G_{z x}=3.5\end{array}$ & $\nu_{x y}, \nu_{z y}, \nu_{z x}=0.4$ & 600 \\
\hline
\end{tabular}

\subsection{Boundary conditions and loading}

The values of the applied loads are taken from Bergman et al. (1993), as it is illustrated in Fig. 3. These values represent loading variation during normal walking. In static analysis, the maximum force of stumbling activity is employed to simulate simplified loading on the implant. This load analysis is based on a selection of the peak-load during stumbling activity. 
The normal walking resultant force $F$ acting on the head of the femur is 8.7 times the body weight $(\mathrm{BW}=70 \mathrm{~kg})$ at $58 \%$ of the gait cycle.

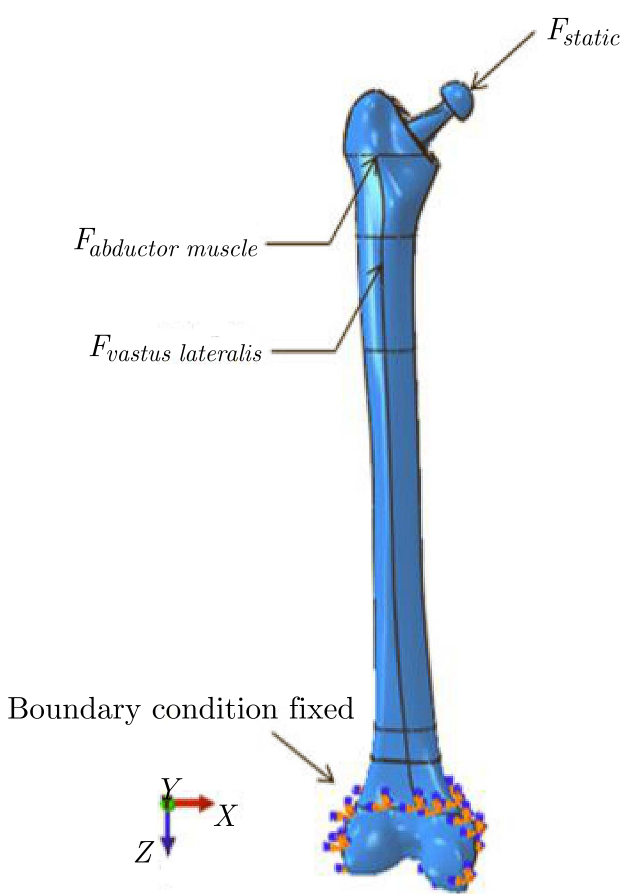

Fig. 3. Boundary conditions and loading of the hip prosthesis

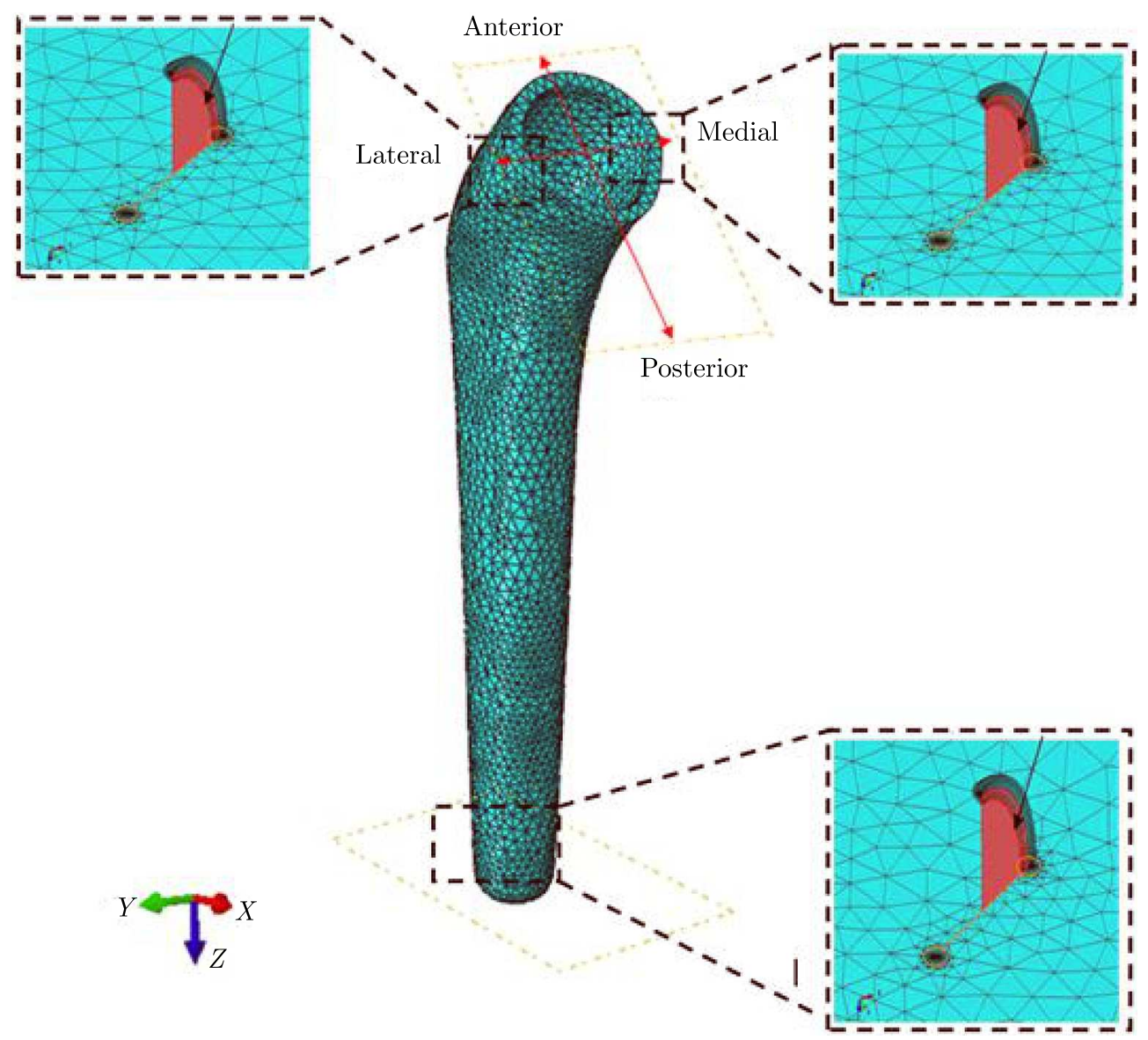

Fig. 4. Three-dimensional model of the crack location 
In this study, the magnitudes and directions of muscles are based on data by Bregmann et al. (2001). The abductor muscle load $F_{\text {abductor-muscle }}$ is applied to the proximal part of the greater trochanter. The iliotibial-tract load $F_{\text {iliotibial-tract }}$ is applied to the bottom of the femur in the longitudinal femur direction as presented in Table 2. The boundary condition is applied by fixing the distal epiphysis, which is the distal end of the femur that is connected to the knee (El-Sheikh et al., 2006). Figure 3 shows the coordinate system where the forces components refer to. The analysis of cracks in different parts of the cement (proximal and distal) is shown in Fig. 4. Real cracks are simulated (Fig. 6), according to the dimensions shown in Fig. 5.

Table 2. Maximum loading configuration of the major muscles (Bergmann et al., 2001)

\begin{tabular}{|l|c|c|c|c|}
\hline Force $[\mathrm{N}]$ & $X$ & $Y$ & $Z$ & $F$ \\
\hline Joint contact force & -433.8 & -263.8 & -1841.3 & $F_{\text {static }}$ \\
\hline Abductor muscle & 465.9 & 34.5 & 695.0 & $F_{1}$ \\
\hline Vastus lateralis muscle & -7.2 & 148.6 & -746.3 & $F_{2}$ \\
\hline
\end{tabular}

(a)

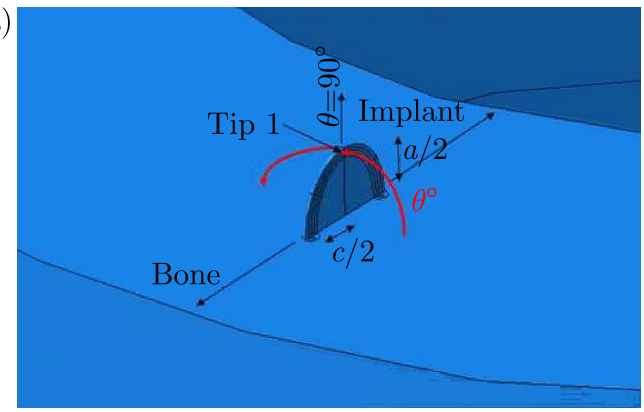

Fig. 5. (a) Dimension and orientation of the crack. (b) Mesh adapted to X-FEM (b)

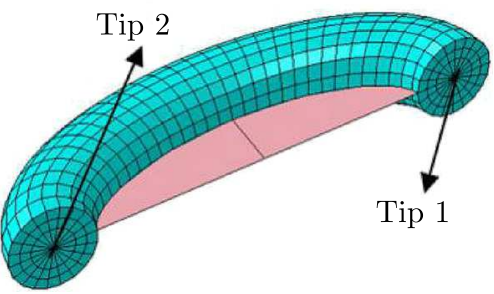

Tip 1

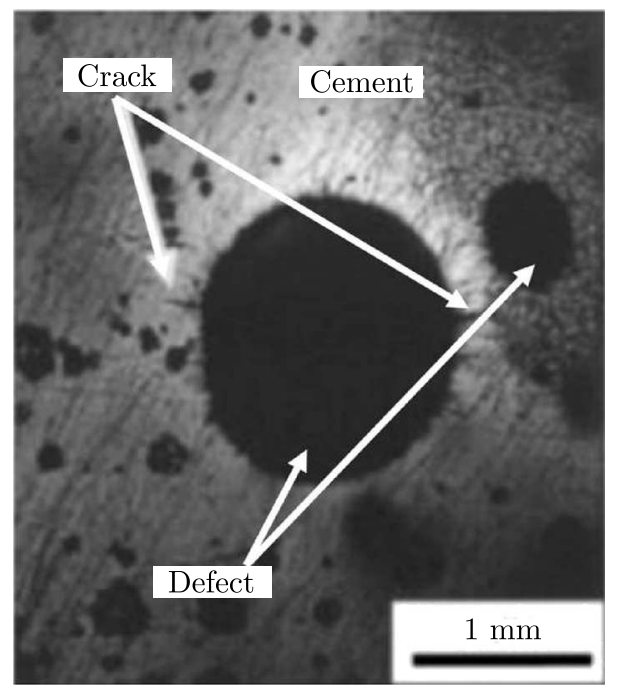

Fig. 6. Cracks in acrylic bone cement observed under transmitted light (McCormack and Prendergast, 1999) 


\section{Analysis and results}

\subsection{Stress distribution in the cement}

A three-dimensional finite element analysis model of von Mises stress applied to the three parts (proximal, medial, lateral, and distal) of the bone cement is shown in Fig. 7. This figure clearly shows that the major stresses are found in the upper region (proximal) where the cement is the most heavily solicited. The other two parts are exposed to lower stresses. The presence of a fragment of the body in this area (cavities, blood bag or bone debris) may be dangerous for stability of the total hip prosthesis. Indeed, such imperfections are the reason for stress concentration by the notch effect. These local stresses can exceed the maximum principal stress of the crack initiation, which can lead to creation and, later, propagation of cracks caused by fatigue. This promotes the risk of the loosening of the total hip prosthesis. Knowing that the cement material has a lower mechanical tensile strength by about $24 \mathrm{MPa}$, one may conclude that stress concentration in the proximal part of the cement, by the notch effect, can lead to total destruction. Later in this paper, this crack behavior is examined thoroughly. This study is carried out by locating the crack initiation area and its orientation in the orthopedic cement.

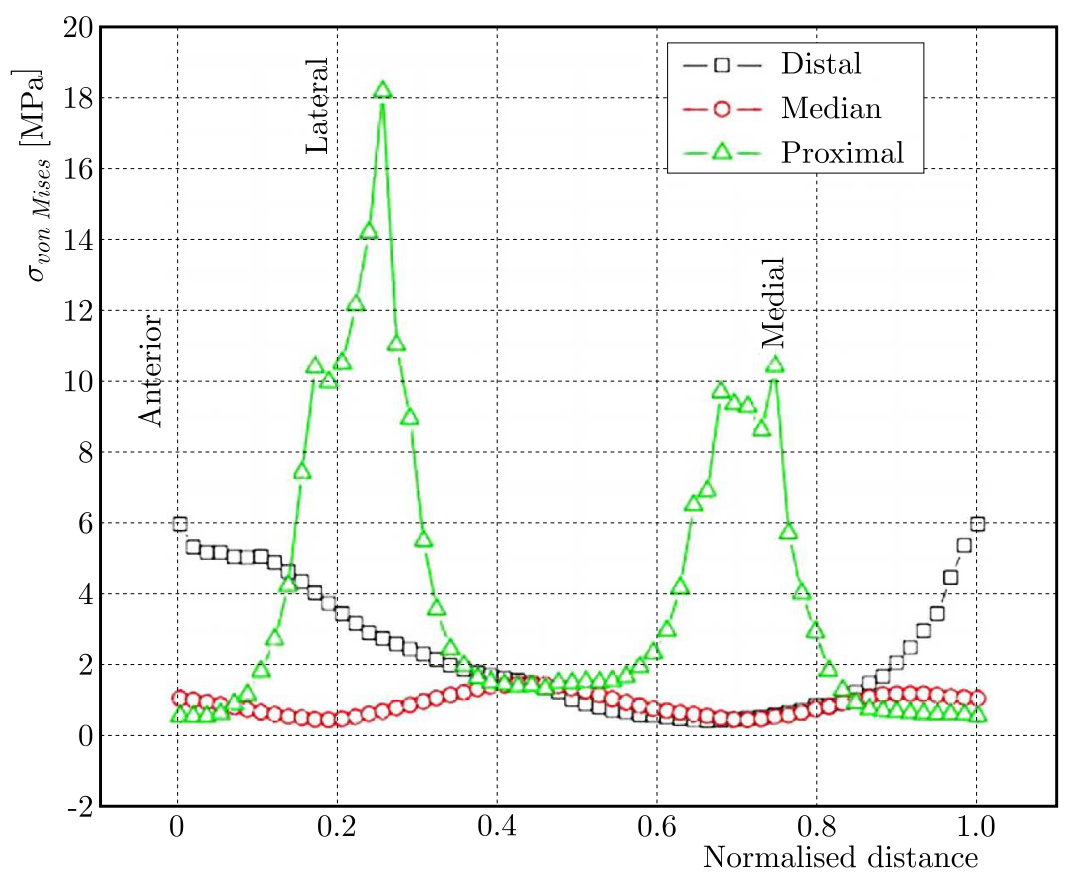

Fig. 7. The equivalent von Mises stress distribution around the cement perimeter in different parts (proximal, medial and distal)

\subsection{Effect of the crack initiation site}

The first elliptical cracks of various geometrical forms are firstly observed at the heart of the cement between the interfaces of the femoral implant-cement and the cement-bone. The analysis of their behavior starts at that area. At first, cracks take place in three areas: proximal (medial, lateral), and distal. This behavior is evaluated in terms of variation of the stress intensity factor and the results obtained are shown in Figs. 8, 9 and 10. Later in this paper, the variation of this rupture criterion is presented in mode I, II and III, according to the size of the crack initiated in these three areas, respectively. The size of the defect is defined by the ratio of the diameters $a / c$. Figure 8 shows the effect of steady progress in the opening mode (mode I) of the crack, located in these three areas, in terms of mechanical energy $K_{I}$ in crack tip 1 and tip 2 (see Fig. 5). This 
figure clearly shows that crack propagation in the direction of tip 1 increases the stress intensity factor in mode I. The criterion of rupture is significant as the crack arises in the lower part of the orthopedic cement, and this practically enlarges the crack (Fig. 5a). The growth of the crack in mode I, following the direction of tip 2, is stopped. The crack tip is stable. The crack propagates practically towards the evolution of point 1 independently of its point of start (Fig. 5b).
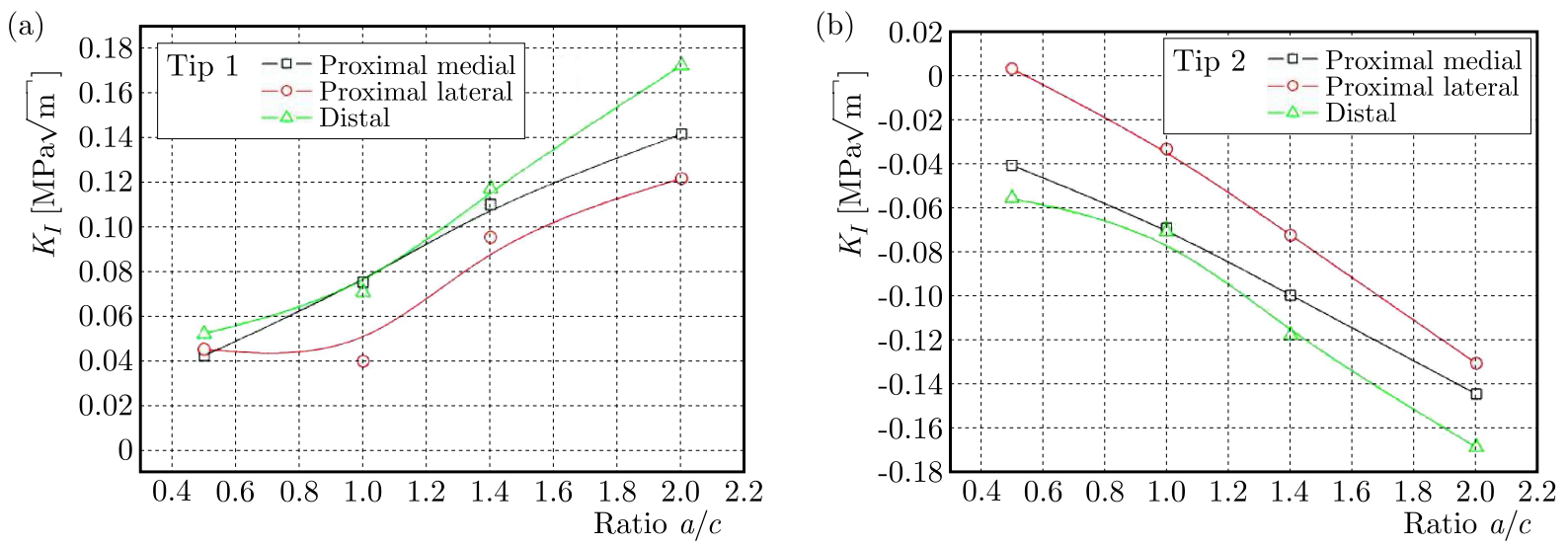

Fig. 8. Stress intensity factors $K_{I}$ in tip 1 and tip 2 for different crack size and priming site
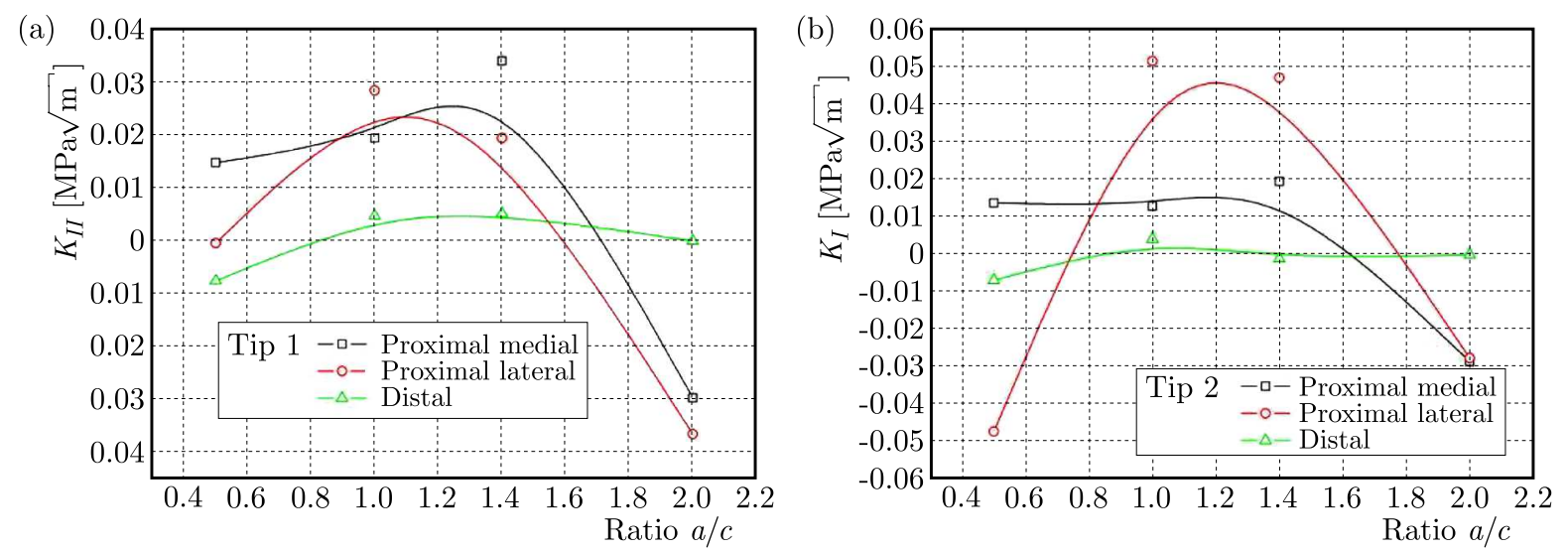

Fig. 9. Stress intensity factors $K_{I I}$ in tip 1 and tip 2 for different crack size and its priming site
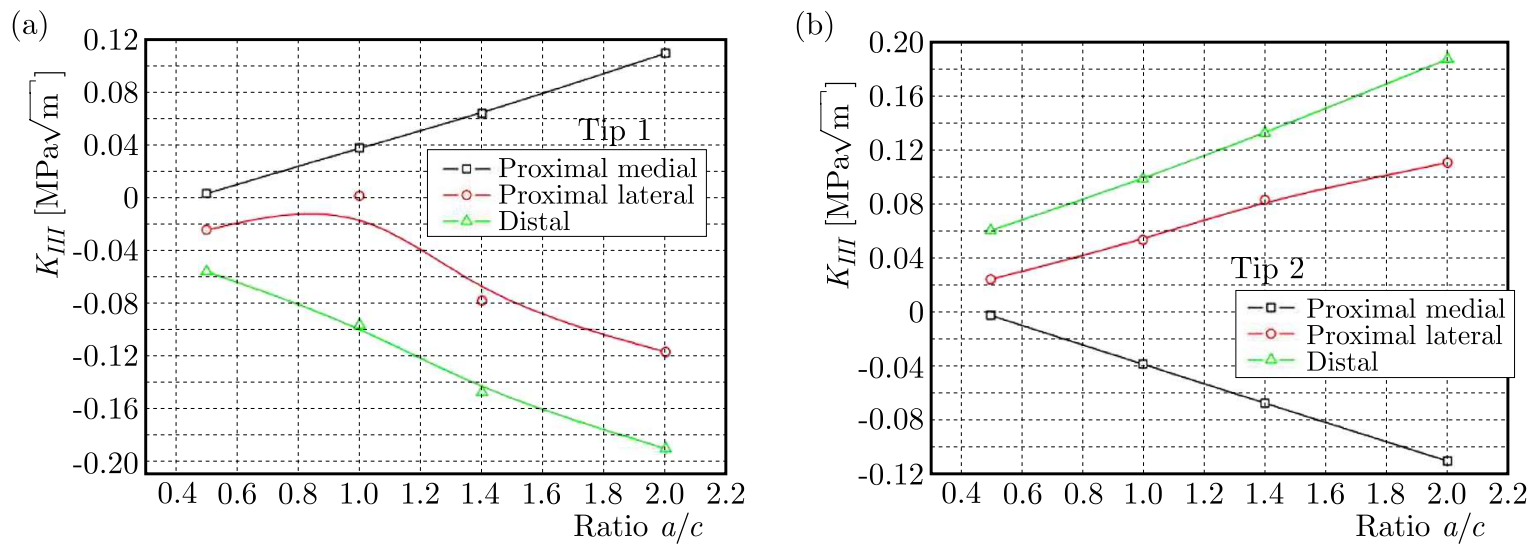

Fig. 10. Stress intensity factors $K_{I I I}$ tip 1 and tip 2 for different crack size and its priming site

In Fig. 9, variation of the stress intensity factor is illustrated in crack tips 1 and 2 in mode II according to the size and location of initiation. A crack in the lateral proximal area follows the 
most important rupture criterion. Such a crack is developed by shear (mode II) in its two tips. Variation of the stress intensity factor in mode III to of crack tips 1 and 2 as a function of the geometric form of the cracks is in the three parts of the cement, as shown in Fig. 10. This figure shows that this rupture parameter increases as the crack evolves independently of its starting point. This evolution is observed in the two tips of this defect. It is the distal part where the crack is unstable. The results obtained in this part of the work show that a crack initiated at the distal part of the cement propagates essentially in mode I and in mode III (mixed mode). In mode II, the crack growth kinetics is virtually null. A crack initiated at the proximal part (medial and lateral) is developed in mode I, in mode II and in mode III (mixed mode). Compared to tip 1, in tip 2, the stress intensity factor is higher. Such a crack propagates essentially according to crack tip 2 .

\subsection{Effect of crack orientation}

The crack initiated in the cement, in its proximal (medial, lateral) and distal parts, undergoes rotation around its center of gravity. The effect of this rotation can be estimated by the stress intensity factor in tips 1 and 2 in mode I, mode II and in mode III. The results obtained are shown in Figs. 11, 12 and 13, respectively. This criterion of rupture in mode I at tip 1 reaches its maximum intensity when the crack is initiated at the distal part and is oriented at an angle of $20^{\circ}$ up to $160^{\circ}$. This crack tip is estimated by the most important tensity factor in mode I, when its rotation is $160^{\circ}$, independently of the area in which it propagates (Fig. 11).

(a)

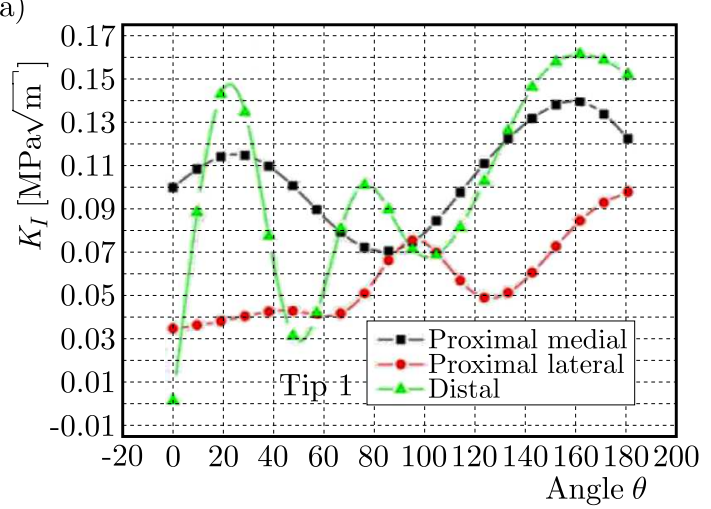

(b)

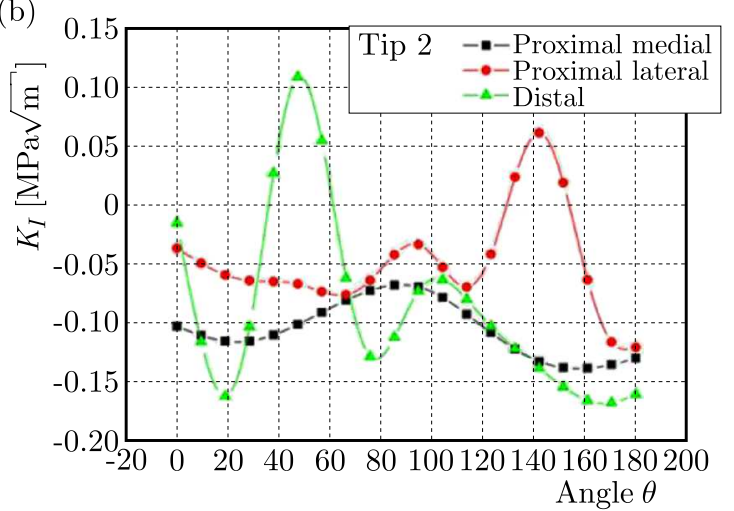

Fig. 11. Stress intensity factors $K_{I}$ tip 1 and tip 2 depending on their orientation and priming crack site; $a=1 \mathrm{~mm}$ and $c=0.5 \mathrm{~mm}$

In this case, this factor gradually drops from the distal part to the proximal part, the medial than the lateral. This criterion of rupture at crack tip 2 takes maximum values when the crack is located at the distal part and is oriented at an angle of approximately $50^{\circ}$. Therefore, there are orientations for which this crack tip is stable, characterized by negative values of the factor (Fig. 11). In mode II, crack tip 1 dominates in the lateral proximal part of the cement, and the greatest important stress intensity factor is obtained in orientations of $20^{\circ}, 50^{\circ}, 80^{\circ}$ and $180^{\circ}$ (Fig. 12a). This criterion of rupture at the crack tip 1, located at the distal part, reaches the greatest intensities, when this defect is oriented at angles of $145^{\circ}$ and $110^{\circ}$. The orientation of the crack, initiated in the medial proximal part at $120^{\circ}$, leads to high factor values in this region of the cement (Fig. 12a). The rupture factor in mode II in crack tip 1, results in a crack located in the lateral proximal part oriented by $20^{\circ}$. Similar behavior is observed for crack tip 2 propagating in mode II as shown in Fig. 12b.

The variation of the stress intensity factor in mode III at crack tips 1 and 2, for the three parts of the cement, is shown in Fig. 13. Figure 13a shows that this rupture criterion at the crack tip 1 is maximum when the crack is initiated at the distal part and oriented at an angle 
(a)

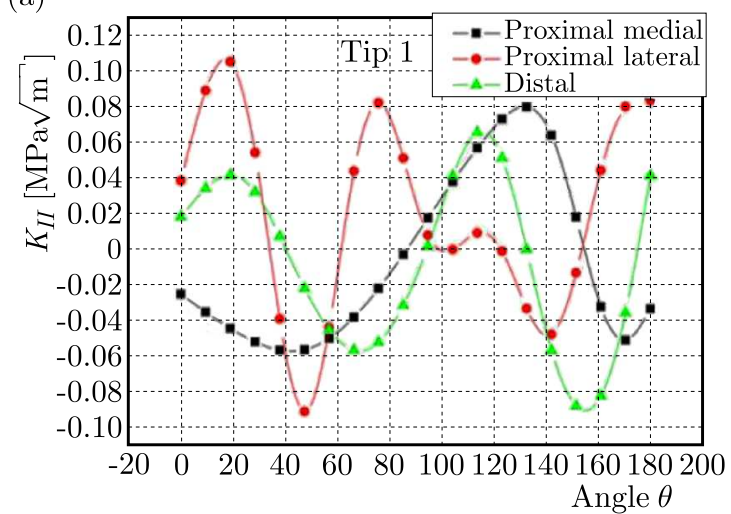

(b)

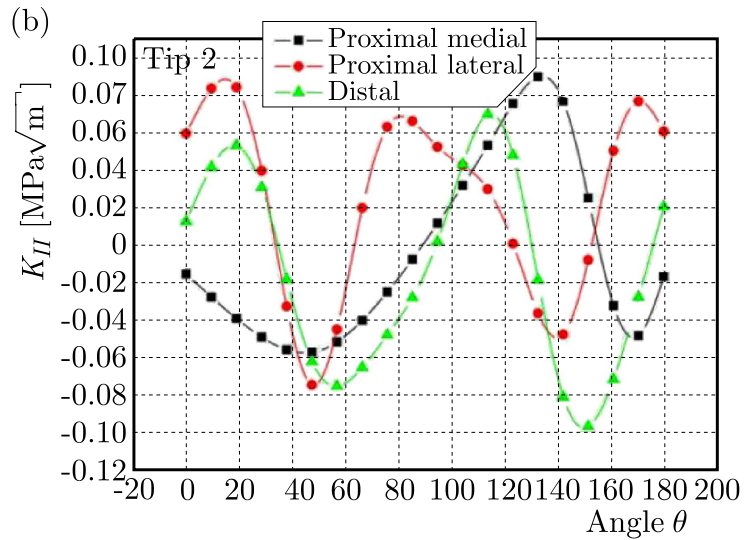

Fig. 12. Stress intensity factors $K_{I I}$ tip 1 and tip 2 depending on their orientation and priming crack site; $a=1 \mathrm{~mm}$ and $c=0.5 \mathrm{~mm}$

of $45^{\circ}$. Compared to other locations of initiation, such a location of the crack leads to high values of the mechanical energy in mode III. A localization of this crack tip in the lateral proximal part leads to a higher intensity, when this defect is oriented at an angle of $25^{\circ}$. This rupture parameter varies among different orientations of the crack initiated in the medial proximal part (Fig. 13a). The stress intensity factor in mode III at crack tip 2 gives the most intense results from the crack tip located in the lateral proximal part of the cement when it is inclined at an angle of $0^{\circ}$ up to $180^{\circ}$ (Fig. 13b), i.e. when the main axis of this crack is parallel to that of the femoral implant. In the distal part, the factor presents two maxima for orientations of $45^{\circ}$ and $90^{\circ}$, that is to say, when the crack is inclined by $45^{\circ}$ on each side of the femoral implant axis. A localization of the crack in the medial proximal part leads to relatively low intensities of the factor.
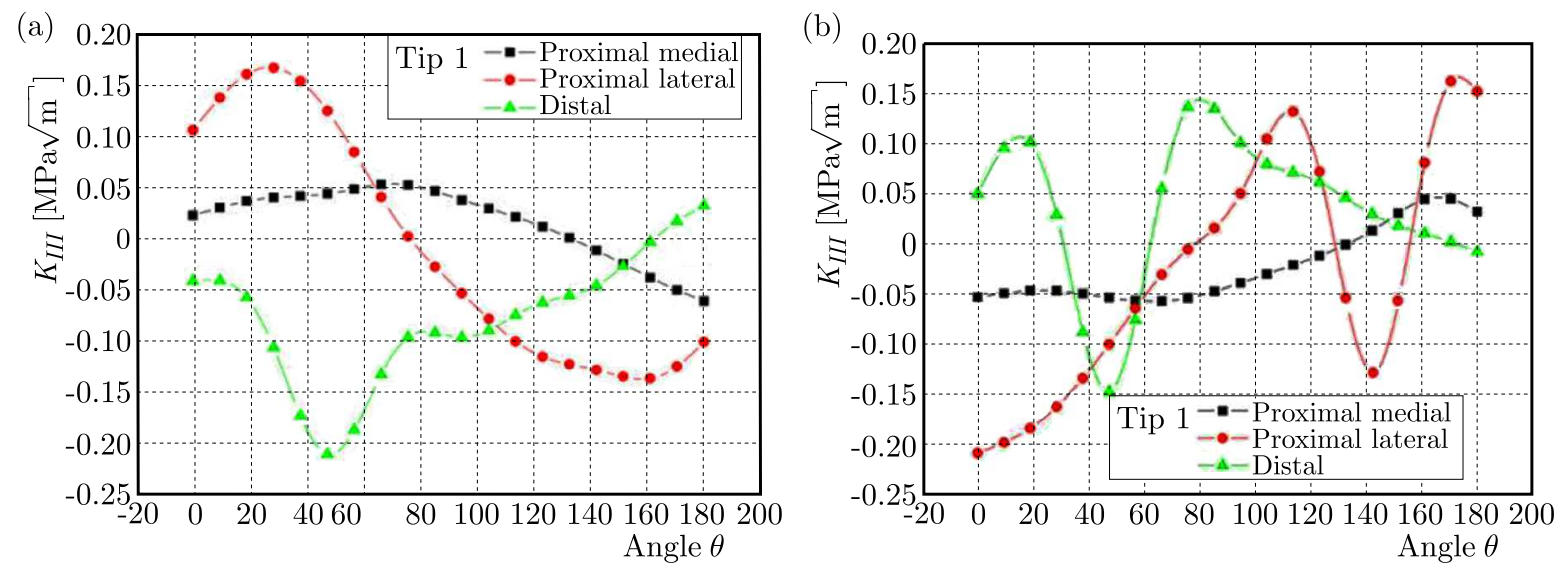

Fig. 13. Stress intensity factors $K_{I I I}$ tip 1 and tip 2 depending on their orientation and priming crack site; $a=1 \mathrm{~mm}$ and $c=0.5 \mathrm{~mm}$

\section{Conclusion}

The results obtained in this work make it possible to extract the following conclusions:

- The equivalent von Mises stresses in the cement are strongly localized in its proximal parts.

- The stress intensity factor in crack tips 1 and 2 depends on the location where the defect is initiated in the orthopedic cement.

- The crack tip 1 initiated at the distal part of the cement propagates essentially in mode I and in mode III (mixed mode). The growth kinetics in mode II is virtually negligible. 
- A crack initiated at the proximal part (medial and lateral) can be developed in mode I, mode II and mode III (mixed mode). In the proximal part, the crack tip propagates in mixed mode I, II and III. Mode I is predominant.

- Crack tip 2, located in the distal part, evolves practically in mode III. Such a tip located at the proximal part develops essentially in mixed mode (II and III).

- The stress intensity factor in mode I, II and III, resulting from crack tips initiated in the cement in its proximal and distal parts, depends on the orientation of the crack. The orientation of $20^{\circ}$ results practically in the highest values of the criterion of rupture in modes I, II and III.

\section{References}

1. ABAQUS Ver 9-11, 2011, User Guide

2. Abdel-Wahab A.A., Silberschmidt V.V., 2011, Numerical modeling of impact fracture of cortical bone tissue using X-FEM, Journal of Theoretical and Applied Mechanics, 49, 3, 599-619

3. Benbarek S., Bachir Bouiadjra B., Bouziane M.M., Achour T., Serier B., 2013, Numerical analysis of the crack growth path in the cement mantle of the reconstructed acetabulum, Materials Science and Engineering C, 33, 543-549

4. Benouis A., Boulenouar A., Benseddiq N., Serier B., 2015, Numerical analysis of crack propagation in cement PMMA: application of SED approach, Structural Engineering and Mechanics, 55, 1, 93-109

5. Benouis A., Boulenouar A., Serier B., 2016, Finite element analysis of the behaviour of a crack in the orthopedic cement, Journal of Theoretical and Applied Mechanics, 54, 1, 277-284, DOI: $10.15632 /$ jtam-pl.54.1.277

6. Bergmann G., Deuretzbachir G., Heller M., Graichen F., Rohlmann A., Strauss J., Duda G.N., 2001, Hip contact forces and gait patterns from routine activities, Journal of Biomechanics, 34, 859-871

7. Bergmann G., Graichen F., Rohlmann A., 1993, Hip joint loading during walking and running, measured in two patients, Journal of Biomechanics, 26, 969-990

8. Bouziane M.M., Bachir Bouiadjra B., Benseddiq N., Tabeti E.M.H., Serier B., BenBAREK S., 2013, The effects of cracks emanating from micro-void and bone inclusion in cemented total hip replacement, Advances in Bio-Mechanical Systems and Materials, Advanced Structured Materials, 40, DOI: 10.1007/978-3-319-00479-2_4

9. El-Sheikh H.F., MacDonald J.B., Hashmi M.S.J., 2002, Material selection in the design of the femoral component of cemented total hip replacement, Journal of Materials Processing Technology, 122, 309-317

10. Griza S., Azevedo T.F., dos Santos S.V., Tentardini E.K., Strohaecker T.R., 2013, Metallurgical failure analysis of acetabular metal-backed screws, Engineering Failure Analysis, 32, $178-187$

11. Lennon A.B., McCormack B.A.O., Prendergast P.J., 2004, The relationship between cement fatigue damage and implant surface finish in proximal femoral prostheses, Medical Engineering and Physics, 25, 833-841

12. McCormack B.A.O., Prendergast P.J., 1999, Microdamage accumulation in the cement layer of hip replacements under flexural loading, Journal of Biomechanics, 32, 5, 467-475

13. Merckx D., 1993, Les ciments orthopédiques dans la conception des prothèses articulaires, Biomécanique et biomatériaux, Cahiers d'enseignement de la SOFCOT, Expansion scientifique française, 44, 67-76 
14. Morgan R.L., Farrar D.F., Rose J., Forster H., 2003, Creep behavior of bone cement: a method for time extrapolation using time-temperature equivalence, Journal of Materials Science: Materials in Medicine, 14, 321-325

15. Najafi A.R., Saffar K.P.A., Arshi A.R., Mallakin E., Katouzian H.R., Eslami M.R., Moeinzadeh M.H., 2011, Propagation of microcracks in bovine osteonal cortical bone, Akademeia, 1, 1, 1923-1504

16. Pilliar RM., Vowles R., Williams DF., 1982, Fracture toughness testing of biomaterials using a mini-short rod specimen design, Journal of Biomedical Materials Research, 21, 145-154

17. Ramos A., Relvas C., Completo A., Simões J.A., 2013, The formation of cracks at cement interfaces of different femoral stem designs, European Orthopaedics and Traumatology, 4, 205-215, DOI: $10.1007 / \mathrm{s} 12570-013-0190-6$

18. Ries M.D., Young E., Al-Marashi L., Goldstein P., Hetherington A., Petrie T., PRUITT L., 2006, In vivo behavior of acrylic bone cement in total hip arthroplasty, Biomaterials, 256-261

19. Rodriguez L.C., Chari J., Aghyarian S., Gindri I.M., Kosmopoulos V., Rodrigues D.C., 2014, Preparation and characterization of injectable brushite filled-poly (methyl methacrylate) bone cement, Materials, 7, 6779-6795

20. Soltész U., 1994, The influence of loading conditions on the lifetimes in fatigue testing of bone cements, Journal of Materials Science: Materials in Medicine, 5, 654-656

21. Taylor D., Hazenberg J.G., Lee T.C., 2003, The cellular transducer in damage-stimulated bone remodelling: a theoretical investigation using fracture mechanics, Journal of Theoretical Biology, 225, 65-75

22. Topoleski L.D., Ducheyne P., Cuckler J.M., 1990, A fractographic analysis of in vivo poly-methyl-methacrylate bone cement failure mechanisms, Journal of Biomedical Materials Research, 24, 2, 135-154

23. WaAnders D., Janssen D., Mann K.A., Verdonschot N., 2012, The behavior of the micro-mechanical cement-bone interface affects the cement failure in total hip replacement, Journal of Biomechanics, 44, 2, 228-234 